\title{
ENGLISH FOR ACADEMIC PURPOSES AND THE ENHANCEMENT OF FRENCH TRAINEE CONTENT TEACHERS' PROFESSIONAL SKILLS
}

\author{
Séverine Wozniak \\ Affiliation: Faculté d'Économie de Grenoble \& ILCEA4 (Univ. Grenoble Alpes), France \\ E-Mail: severine.wozniak@univ-grenoble-alpes.fr
}

\begin{abstract}
This paper explores the issue of syllabus design for English for Academic Purposes (EAP) classes by presenting a case study carried out at the Grenoble Faculty of Economics and the Grenoble Initial Teacher Training College (France). The study had two objectives: develop prospective and newly recruited content teachers' professional skills, notably the ability to teach their subject in English on an occasional basis, and help them reflect on their professional practice. In order to do so, mandatory EAP modules for all trainee content teachers (TCT) of disciplines other than language studies were implemented to provide TCTs with an introduction to content and language integrated learning (CLIL) and to train them to teach in a CLIL format. In this paper two types of data are analyzed: the assessment of TCTs' final assignment and the responses to a questionnaire aiming at gathering TCTs' feedback on the EAP modules.
\end{abstract}

Key words: content and language integrated learning (CLIL), English for Academic Purposes (EAP), pre-service teachers, trainee teachers

\section{INTRODUCTION}

The 2013 overhaul of the French Master's Degrees in Education's ${ }^{i}$ national curriculum has provided the opportunity to include specific requirements as far as newly recruited teachers' language competencies are concerned. As the promotion of Content and Language Integrated Learning (CLIL) in French higher and secondary education has been on the rise in recent years, in the general perspective of the implementation of the Bologna Declaration promoting increased compatibility between the various European higher education systems in order to promote citizens' mobility throughout Europe, the new curriculum specifies that teachers' training should include a mandatory language module aiming at making sure trainee teachers master at least one foreign language (Article 8). Besides, this new curriculum puts the emphasis on the prospective teachers' professional skills, notably the ability to observe and reflect on their professional practice (Article 7). It refers directly to the framework for professional skills in education, ${ }^{\mathrm{ii}}$ which includes the ability for teachers to use a foreign language in a professional context at a B2 level and take part in the development of pupils' intercultural competencies.

In the context of the implementation of this national curriculum, the Grenoble Initial Teacher Training College (Ecole supérieure du professorat et de l'éducation-ESPE) decided to introduce mandatory modules in language for academic purposes for all trainee content teachers (TCTs) of disciplines other than language studies. With the aim of embedding this language module into teachers' professional education, the ESPE

Submitted September $11^{\text {th }}, 2018$, accepted for publication October $31^{\text {st }}, 2018$ 
required all EAP lecturers who taught these modules to focus on an introduction to CLIL and CLIL specific teaching skills. The present paper explores the issue of syllabus design for EAP classes, through a case study in this specific context. What are the skills that prospective and newly recruited content teachers have to acquire as part of their initial training? How can they be helped to reach this objective?

\section{APPROACH \& METHOD}

Recent findings in CLIL training and pre-service teachers' training were analyzed in order to frame our research project. We looked specifically at definitions of general teaching skills for novice teachers (Haigh et al., 2013) and at skills specific to the context of CLIL teaching. CLIL is defined here as "a pedagogical approach with a dual focus, involving the integration of language study with the study of a subject domain as aims of instruction" (Greere \& Räsänen, 2008, p.4). The development of CLIL in Europe should be put into the larger perspective of the implementation of the language policy conceived by the European Commission and the Council of Europe:

One of the first regulations concerning CLIL was passed in the European Union in the 1995 Resolution of the Council, which aimed to establish innovative methods within education and drive bilingual policies by teaching content areas in a foreign language rather than restricting it to the traditional linguistic subject. (GuillamónSuesta \& Renau Renau, 2015, p.3)

Our first objective was to explore the appropriate granularity in the definition of our project: what kind of CLIL teaching are we talking about? Greere \& Räsänen $(2008$, p.6) proposed a five-step approach to CLIL, from non-CLIL to LSP/discipline-based language teaching, pre-CLIL (focusing on content), adjunct-CLIL (comprising "language support coordinated with/integrated in subject studies" taking place simultaneously) to CLIL (as a "fully dual approach and full integration of language across subject teaching by subject specialist or via team teaching"). The objective of Grenoble ESPE was to reach the fully dual approach that appears at the CLIL level. In order to reach this objective, we decided to focus on the 4Cs Framework defined by Coyle (2006) to qualify the relevant elements when considering the issue of CLIL:

(1) Content: it refers to the individual acquisition of knowledge, understanding and development of the skills of a specific content subject that students are supposed to perform.

(2) Cognition: it is connected to the thinking processes that enable both concept learning and linguistic demands simultaneously.

(3) Communication: it is used to learn and reconstruct the input given as well as to interact in the foreign language within the learning context.

(4) Culture: it is essential in CLIL because it makes students aware of the relationship between languages, cultures, history and themselves. (summarized in Guillamón-Suesta \& Renau Renau, 2015, p.2)

Our study was carried out in order to identify how to train content teachers to teach in a CLIL format. First, in order to make sure we could assess teaching competencies, we turned to the evaluation of teaching performance carried out by the Centro de Estudios $e$ Investigaciones Docentes (CEID) in Spain, which includes 28 items grouped into three subcategories: planning, development and results. As the TCTs taking part in this project 
are first year M.Ed./MEEF students, this case study focuses only on planning; the CLIL lessons will not be implemented in authentic classroom situations, but presented and discussed among the group of TCTs. The items put forward by the CEID as far as planning is concerned are: "He/She presents the minimum content of his/her subject matter, tailored to the students' knowledge; He/She provides clear information about objectives, bibliography, tutorials, contents, and assessment methods in the subject's curriculum; He/She presents the contents following a clear and logical framework, highlighting the important aspects" (Moreno-Murcia et al., 2015, p.57). We also surveyed previous research regarding the definition of specific teaching skills in the context of CLIL, a real challenge for novice teachers:

Teaching curriculum subjects through the medium of English means that teachers must convey not only the subject content and disciplinary language but also the practical problem-solving, negotiations, discussions and classroom management in ways that characterise disciplinary pedagogic practices. (Graddol, 2006, p.86)

In fact, as Hillyard puts it, "[...] CLIL teachers need three separate but intertwined abilities in order to operate within this new approach: target language ability, content knowledge, and CLIL methodology" (2011, p.5). The objective of the EAP lecturer was to raise TCTs' awareness of the opportunity to foster their pupils' ability to study different subjects in a foreign language. Thus, TCTs had to be guided into taking their future pupils' language ability into account, notably by helping them with language in their teaching. As stated by Basturkmen \& Shackleford, "teachers in school contexts support their students' learning by highlighting the most appropriate language to use in terms of the general academic or a discipline-specific register", stressing the fact that an efficient way to help pupils was via "more self-repetition and rephrasing, particularly when introducing new conceptual information and terminology to classes of non-native speaker students" (2015, p.87). In this perspective, what syllabus would most help TCTs?

This case study involved prospective and newly recruited French trainee teachers of economics and management at the Grenoble ESPE and the Grenoble Faculty of Economics. The TCTs involved in our case study are enrolled in the first year of their M.Ed./MEEF and are taking the French national competitive exams ("certificat d'aptitude au professorat du second degré/CAPES" and "Agrégation") that will grant them a tenured position to teach economics and sociology or management in French vocational or general upper secondary schools. During the first year of this M.Ed./MEEF program, the design of this mandatory EAP module followed three steps: (1) definition of the objectives for the module; (2) design of the syllabus; (3) assessment of the quality of the final assignment of teaching materials produced by the EAP lecturer. TCTs filled in a questionnaire at the end of the module, providing feedback on its effectiveness and usefulness. This feedback also constitutes data for the case study.

The general objective of this EAP course was to help TCTs feel comfortable enough to teach some of their senior high school classes in English on an occasional basis. The premise of such teaching is quite artificial: there is obviously no need to communicate in English as all participants in the planned high school CLIL sessions will be French speakers. Another objective of the EAP class is to help build TCTs' professional skills, particularly by making them aware of the value of their involvement in innovative teaching approaches and accompanying them in building a reflexive stance on their own professional practice. To this end, they need to be able to describe expectations, 
requirements, prerequisites and objectives in a foreign language, from both linguistic and discipline-related points of view, even though they are not actually teaching yet. In fact, this approach should be considered in the general perspective of "learning by teaching" methodologies for trainee teachers:

\begin{abstract}
Learning by teaching is a learning and teaching approach that sees students as being able to assume the role of a teacher, enhancing their own learning and knowledge of any subject matter while being encouraged to teach the knowledge they have just acquired to other students (Stollhands, 2016). Karimi (2011) and Roscoe and Chi (2007) indicate that when students teach or tutor other students, the students achieve more solid learning goals. Similarly, Nestojko (2014) affirms that students recall material, organize content, and manipulate information more correctly when they plan to teach other students than when they prepare to take exams [...]. This practice should be followed throughout the teaching career to achieve day by day better professional growth. (Gomez, 2017, p.23)
\end{abstract}

The grid we used to design the syllabus, and more particularly the main assignment, was developed by Bertaux et al. in order to promote best practices in education and to "serve as a framework for developing pre-service or professional training courses for CLIL" (Bertaux et al., 2009, p.1). In our syllabus design stage, basic pre-requisites had to be taken into account in order to make sure the TCTs could "communicate using contemporary social registers/adjust social and academic registers of communication according to the demands of a given context" (Bertaux et al., 2009, p.2) and that they mastered the general language of teaching: "explaining, giving instructions, eliciting techniques, the language of classroom management, and the language of learning activities" (Hillyard, 2011, p.7). Then, time was devoted to develop their Cognitive Academic Language Proficiency (CALP) (Bertaux et al., 2009, p.3), helping them to develop their ability to "read subject material and theoretical texts, use appropriate subject-specific terminology and syntactic structures, conceptualise using the target language" (Bertaux et al., 2009, p.2). We ensured they were given enough input in order to be able to use English to "explain, present information, give instructions, clarify and check understanding, check level of perception of difficulty" and helped them to select and adapt teaching materials (Bertaux et al., 2009, p.3). The syllabus of this EAP course also includes some general basic economics topics (particularly the key terms and concepts included in the syllabus of the economics and management courses in French senior high schools), as well as conventional EAP topics focusing on the specialized language and domain of secondary school education in the US (how secondary school teachers are recruited and trained, their working conditions, the topical issues in the field of US education today, etc.).

The main assignment for the course was designed to test whether the course participants would be able to meet their pupils' discipline-related needs and provide intercultural insight on discipline-related issues. TCTs were asked to do an individual ten-to-fifteen-minute oral presentation, followed by a discussion during which their peers discussed their proposal. As the TCTs are novices, this assignment is supervised and comprises a step-by-step design of the whole lesson plan with a particular focus on the CLIL session they have to devise. Moreover, several elements have to be included in the oral presentation, e.g., the target class level has to be specified and should ideally be the level in which their mandatory class observation period took place. The lesson's general topic, the concepts and key terms, overall instructional time, and preparation materials also have to be clearly stated. The lesson's general topic is usually covered within three 
or four class sessions, and these have to be broadly described in terms of contents and teaching objectives. A focus on the third session, the CLIL one, is expected. The lesson plan for the CLIL session should be detailed and incorporate: a bell-ringer activity and two other teaching activities, among which the use of at least one video or animated presentation. This video requirement was included in line with the CLIL Teacher's Competences Grid, and specifically the promotion of cultural awareness, as TCTs are expected to be able to: "select and adapt authentic material from different regions or countries, articulate key cultural parameters associated with the CLIL language, guide students in developing cultural awareness", "raise learners' curiosity about the culture(s) related to the CLIL language" and help pupils avoid stereotyping (Bertaux et al., 2009, p.6). At the end of their talk, TCTs have to specify the nature of the written record their pupils will hold at the end of the CLIL session and how the planned learning outcomes set for this session would be assessed. In order to pass this final assignment, the TCTs had to meet several criteria: whether they met the time and content requirements (with a particular focus on the written record and the assessment and evaluation procedures they suggested), whether the video or animated presentation they picked was relevant and of appropriate length, whether they were able to take the intercultural dimension of the activity into account, and eventually, how they handled the reflexive dimension on their own proposal as future professionals during the debate after their presentation.

Out of 15 students enrolled in this EAP course, 14 took part in the project. One of them, who did not choose a subject in relation to economics, sociology or management, had decided to change her professional project and try to become a primary school teacher instead ${ }^{\mathrm{iii}}$. As far as the topics are concerned, TCTs covered the syllabus implemented in senior high schools in economics, sociology or management at all levels, from freshman year (general introduction to economics) to high school diploma level classes (French baccalaureate) and the two-year higher education level vocational degree that French students can take in senior high school (See Table 1).

Table 1 Subjects dealt with by the TCT for the EAP assignment

\begin{tabular}{|lll|}
\hline Economics & Management & Marketing \\
\hline introduction to economics & $\begin{array}{l}\text { SWOT analysis } \\
\text { strategic management } \\
\text { income distribution }\end{array}$ & brands and product identification \\
competitive markets & management styles & \\
law of supply and demand & & \\
wealth creation, measurement & & \\
and distribution & & \\
market and non-market & & \\
production & & \\
economic growth and & & $\mathbf{3}$ \\
environmental protection & & \\
consumption & & \\
imperfect competition & & \\
sustainable development & & \\
\hline
\end{tabular}




\section{RESULTS}

Two types of data were gathered for this case study: first, the assessment of the final assignment, which was carried out by the EAP lecturer in charge of this course, and second, the TCTs' feedback. Some of the difficulties they encountered were related to oral presentation skills:

- inadequate time management in the preparation phase: they had not realized it would take so much time to prepare this project. One of them had to drop out at the last minute as she had difficulty doing anything (the first year of M.Ed./MEEF is particularly busy, as TCTs have to simultaneously prepare for the national competitive exam, perform classroom observations, and attend and actively participate in Master's courses and seminars),

- lack of anticipation of the many technical glitches that can occur,

- inadequate level of language skill, and lack of implementation of the appropriate language learning strategies (be they cognitive or metacognitive).

For some TCTs, the content itself made the whole assignment troublesome. Managing instructional time constraints and prerequisites for the lesson also remains challenging for novice teachers. They also had difficulty with the written record pupils are supposed to have at the end of the CLIL session and with the design of appropriate assessment (How to make sure the CLIL session's learning objectives were reached?). Other pitfalls were directly linked to the fact that they did not anticipate some key issues related to language teaching, i.e., some of them overestimated the expected level of high school pupils' language ability when selecting the video (in terms both of length and content) and most of them were unable to identify the elements within the various oral, video and written documents they proposed to use that could make understanding easier for their pupils. They also did not take into account the fact that pupils were expected to interact orally more during a CLIL session than during a traditional lesson carried out in French. However, one major challenge is the fact that most of them failed to consider the intercultural aspect that is one of the key components of CLIL teaching. Instead of seizing the opportunity to use and refer to American high school economics textbooks, for instance, they used French textbooks, and referred to French cultural examples (e.g., illustrating the notion of market vs. non-market production with the examples of a "Yves Rocher" shop, a "Pôle Emploi" local job center and a French "boulangerie").

The second type of assessment was provided via an anonymous questionnaire filled in by each TCT at the end of the last session. Only open-ended questions were used, to elicit feedback on their general experience and especially in relation to the EAP course's professionalizing aspect. Sixteen responses were gathered. The first questions dealt with the general context: the individual TCT's result on the placement test ${ }^{\text {iv }}$ (based on the CEFR grid), the subject of the bachelor's or master's degrees they held and the type of competitive exam they were taking at the end of the academic year. Another question was about whether they had already taken any ESP (English for Specific Purposes) or EAP courses and the main difference they could perceive between those and general communication courses, to which 13 out of 16 replied in the affirmative. As expected, TCTs identified what they called "vocabulary" (but is in fact terminology) as the main feature of EAP courses. Many of them also mentioned the fact that, within an EAP course, the various tasks and exercises for practicing the five basic language skills are 
adapted to the students' specialization. The terms they employed to define the EAP course were: "useful", "operational" and "professional" (See Table 2).

Table 2 Responsesv to the question:

"According to you, what is the main difference between EAP and general communication courses?"

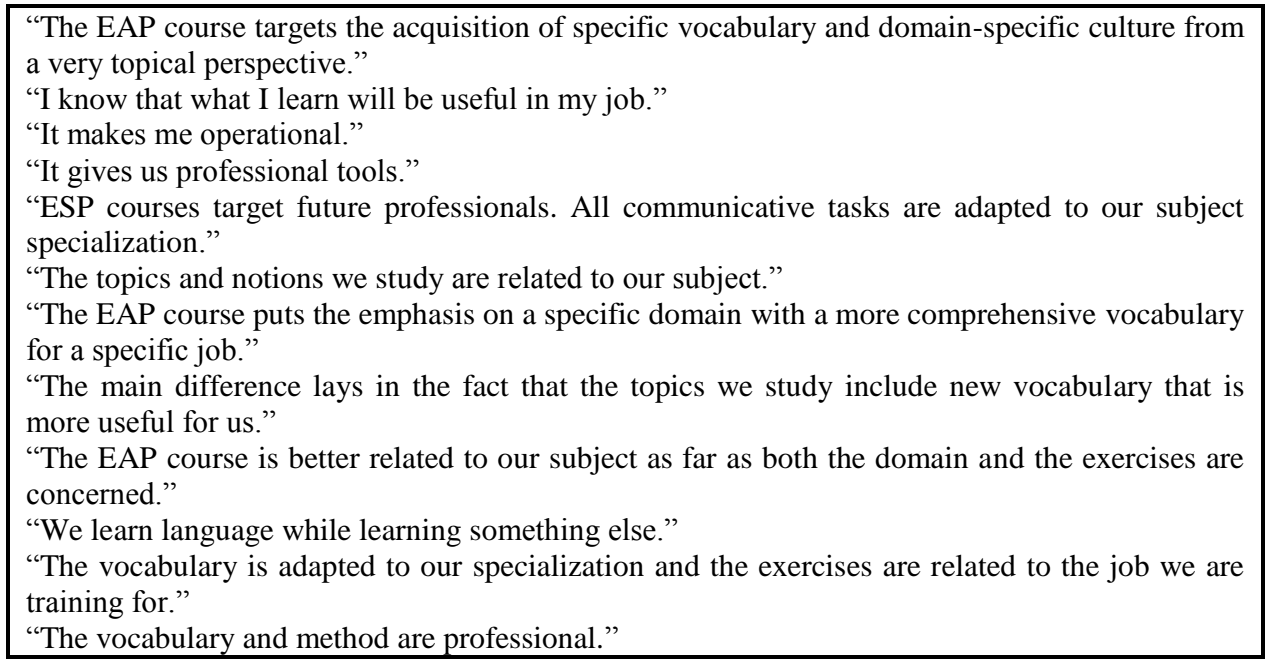

The next questions dealt with the final assignment itself and were grouped in three sub-categories: anticipation, preparation and implementation, and ex-post perception. In relation to anticipation, TCTs were asked about their feelings when the CLIL session project was first presented: 5 of them anticipated this would require a lot of work, 2 of them were scared, as the final assignment mixed "English skills, content knowledge and pedagogy (methodology on how to create a new course)". The final assignment was perceived as complex, difficult and very abstract since it was first introduced at a time of the academic year when TCTs have just started to learn in French how to design lesson plans; they expected it to be even more difficult to do in English than in French. However, some of them had positive reactions (See Table 3).

Table 3 Responses to the question:

"What did you think when the project was first introduced?"

"I thought first that this exercise was down to earth and related to what we do in the didactics of economics course."

"I thought that it was a very good idea as learning how to teach your subject in another language is formative."

"Interesting idea. I've decided to use a short video to introduce the various topics even in French. I was also curious to see what the other TCTs were teaching."

"This assignment was a specific type of exercise for our training as teachers, which led us to work in the same way as we do in our didactics of economics course but in another language." "Attractive as it puts together the English and the didactics for economics courses." 
Most of them initially thought that they would be able to do it, with only 4 of them answering with a clear "No" to the question: "Did you think you would be able to do it?". Those who questioned their ability to carry out the project expressed a lack of belief in their language ability. Only one of them expressed doubts about their capacity to be good enough in the subject ("I was scared to be judged on content: the fact that my CLIL session had to meet the requirements and expectations for economics courses at freshman level."). The personal qualities and skills that made them confident in their capacity to succeed were the following: "good oral communication skills in English", "capacity to find recent and attractive documents", "to design an appropriate lesson plan", "perseverance", "motivation", "organization" and "creativity". Some of them also stressed the fact that the instructions were easy to understand and to follow. The difficulties they anticipated were mainly related to their oral presentation skills in English (being able to present in English without reading their notes) and terminology. One of them referred to the difficulty for pupils to understand economics in English ("Economics is difficult for pupils, even more so in English.") and another one to take a reflexive stance: "Being understood by my peers in the debate", "Explain in English what I expected to pupils to learn".

Regarding the final assignment's preparation and implementation phase, 14 out of 16 TCTs found that the elements given by the EAP lecturer helped them feel guided in the step-by-step design of their CLIL session, stressing the fact that "the template for the structure of the talk was useful" and that instructions and explanations were clear and objectives were clearly set ( 7 out of 16 used the resources put on line by the EAP lecturer). In order to prepare their assignment, just a few of the TCTs asked for some help: one of them asked their cousin, who is a freshman, to test the project and see what she did/did not understand, another one asked "A friend who is fluent in English", one of them prepared the final assignment with their mentor. In preparing the final assignment, planning the lesson, finding a topic, finding and designing the activities, "organizing the layout of the final version of the documents", "the expected level of content-knowledge (as the exercise was on the whole quite short)" were finally perceived as easier than the TCTs expected. Conversely, 9 out of 16 found choosing an appropriate video or animated presentation more difficult than expected. Other complications included: finding relevant activities and documents, time management during the oral presentation, interaction with the other TCTs during the debate, "being specific enough in English to be sure pupils understood what they had to do", "adopting a reflexive stance on my work". Paradoxically, they often found more difficult what they expected to be easy: one TCT found it difficult to find an appropriate video but had initially thought she would be able to retrieve recent and attractive documents, and another TCT had trouble with oral comprehension even though he considered himself "good in English oral communication".

Finally, as far as TCTs' ex-post perception of the CLIL session project was concerned, 9 out of 16 answered with a clear "Yes" (See Table 4) and 4 with a clear "No" to the question: "Now do you feel able to implement a CLIL session?". This could mean that the objective of building self-confidence in teaching CLIL for those TCT who master both content- and language skills was reached. Those who did not feel able to do it mentioned the fact that they were "not good enough in oral English" or needed more "time to master all the notions in French and in English". 
Table 4 Responses to the question:

"Now do you feel able to implement a CLIL session?"

"Yes: now it appears to me that it is doable!"
"Yes and No. I need to work more on my oral presentation skills."
"Attractive for the pupils to teach a one-hour CLIL session from time to time as it breaks the
weekly routine, but means much more work for the content teacher."
"It's interesting for pupils and different from traditional forms of teaching."
"I don't know whether I would be able to do it by myself, but I think I can do it provided I get
some help from the English teacher."

"I could do it and talk about the experience with the other TCTs in the course."

This goes in line with the conclusion reached by Gomez regarding his study on the introduction of inquiry-based learning (IBL) in an English as a Foreign Language (EFL) literature class of a foreign language teacher education program at a public University in Bogotá (Colombia):

This research study indicates that pre-service teachers became aware of the need to improve their teaching skills, when they invested in their pedagogical knowledge and assumed a responsible teacher role in order to be well-prepared with the contents and methodologies to teach a class on short stories in the EFL classroom. They realized that careful preparation, planning, and research is needed, before a teacher actually teaches a class on content and leads a student-centered environment. (Gomez, 2017, p.32)

Nine out of 16 acknowledged the interest of working in pairs with the language teachers in their future institutions, even if they already had this intuition before starting working on the CLIL session project. They recognized that, even though such projects are beneficial for both content and language teachers, and pupils, they are time-consuming and sometimes hard to implement. The overall view of the EAP module seems positive, as 15 out of 16 TCTs believed that it had helped them build professional teaching skills (See Table 5).

Table 5 Responses to the question:

"This EAP course was designed as part of a professional skills-based approach to novice secondary school teachers' training. Do you think this objective was reached?"

"Yes, as the very concrete aspect and the vocabulary input was all in the perspective of building professional skills."

"Absolutely, the final assignment on the design of the CLIL session fit exactly among the development of our professional skills."

"Yes, I think I developed professional oral skills."

"Yes, as we could put what we will have to do as teachers in practice."

"The course brings complementary components and a new perspective."

"It gave us an initial experience."

"I think I am able to teach in English and I think it is important for pupils to learn economics in English as it is topical and matches the requirements of the labor market." 


\section{CONCLUSION}

This paper explored the issue of EAP in relation to CLIL teaching in French secondary schools. Previous research has tackled the challenges and implications for EAP of the promotion of CLIL at university level. For example, Arnó-Macià \& Mancho-Barés focused on the implementation of CLIL programs at a Catalan university in the fields of agronomy engineering, business and law from an EAP perspective. Even if their study shows "a certain enthusiasm towards CLIL, perceived as a real communicative context for discipline-oriented language use", overall, much remains to be done before CLIL teaching in Spain is truly effective:

Despite institutional policies towards CLIL and instructors' and students' enthusiasm, CLIL implementation is regarded at present as an insurmountable obstacle, left to the goodwill and effort of content lecturers who often have to deal with low proficiency levels (generally that of students, but also often their own). (Arnó-Macià \& Mancho-Barés, 2015, p.72)

Similarly, the declared objectives of Grenoble ESPE's EAP module are highly demanding: to develop prospective teachers' professional skills, notably the ability to teach their subject in English on an occasional basis and to reflect on their professional practice. The challenge also lies in the fact that, in the French context, unlike in many other European countries, CLIL teaching at secondary school level is still not common, except in some optional bilingual classes. Many of our findings are consistent with those of a 2015 study that attempted to analyze the attitudes and views of language and content teachers in Spanish secondary schools regarding CLIL, as 92,3\% of the content teachers who participated in the 2015 study "argued that they were not sufficiently confident or prepared to perform a class in the foreign language, even though $30 \%$ of them presented a B2 level" (Guillamón-Suesta \& Renau Renau, 2015, p.7). In relation to the implementation of CLIL, $80 \%$ of them were afraid the class's usual teaching and learning pace would be affected by CLIL and they also identified other difficulties linked to CLIL methodology and teachers' and learners' language proficiency.

With this in mind, we identify several ways of improving this EAP course, in line with Hillyard's CLIL teacher's competencies grid, which includes the following: "a shift in attitude to include a willingness to change, the desire to learn something new, motivation to learn the 'whys, whats, and hows', a willingness to work with others (and to link the CLIL programme with school ethos), a willingness to design materials andabove all - a belief in the efficacy of CLIL" $(2011$, p.6). In our case study, one of the teaching objectives is that EAP lecturers should help TCTs build self-confidence in their language skills. Therefore, the utility of organizing a pre-module placement test should be questioned, as the requirements are the same for all TCTs, both in terms of CLIL teaching and language ability. The test is therefore irrelevant and is perceived as a deterrent or "de-motivator" for TCTs ("I'll never be able to do it"). Another way to improve the EAP module would be to increase cooperation with other teachers, particularly language teachers and even team teaching should be better promoted by the EAP lecturer. Similarly, content teachers could help language teachers in selecting documents that meet the general curriculum, i.e., implementing foreign language goals in content teaching. The objectives of the two approaches appear complementary: 
The goals, however, are different in that content-based instruction for ESL [English as a Second Language] is designed to help students make a successful transition to the all-English curriculum, whereas the foreign language goal of Connections ${ }^{\mathrm{vi}}$ is intended to help students "use their developing language skills to go beyond the requirements for class work and pursue topics further for personal interest, unrelated to the limits of academic life" (ACTFL, 2006, p.53-54). It may be that such differing goals elicit different types of motivation: the ESL model may motivate students by holding out the carrot of academic success in the target language, while the FL model may motivate students by providing access to the development of their personal interests. (Chamot \& Genovese, 2009, p.151)

Third and most importantly, the linguistic and intercultural aspects of the project should be emphasized, by stressing the fact that TCTs should use resources in English, for terminology and teaching resources. This could be done by planning one of the EAP course's lessons on the analysis of American and British high school economics textbooks, for example. The challenge for EAP lecturers is to ensure that, in the future, French secondary school pupils will often be taught many different subjects in English, and be able to learn content and language simultaneously. This is entirely feasible, as Taillefer argues:

Encouraging the implementation of effective CLIL is a major challenge, but the fruit of several decades of French ESP research and expertise in various domainspecific epistemologies, cultures, terminologies and discourse bodes well for such an undertaking. (2013, p.48-49)

\section{REFERENCES}

American Council on the Teaching of Foreign Languages (ACTFL). (2006). Standards for foreign language learning in the $21^{\text {st }}$ century. Lawrence, KS: Allen Press.

Arnó-Macià, E. \& Mancho-Barés, G. (2015). The role of content and language in content and language integrated learning (CLIL) at university: Challenges and implications for ESP. English for Specific Purposes, 37, 63-73. Retrieved June 5 ${ }^{\text {th }}$, 2018, from http://dx.doi.org/10.1016/j.esp.2014.06.007.

Basturkmen, H. \& Shackleford, N. (2015). How content lecturers help students with language: An observational study of language-related episodes in interaction in first year accounting classrooms. English for Specific Purposes, 37, 87-97. Retrieved June $5^{\text {th }}, 2018$, from http://dx.doi.org/10.1016/j.esp.2014.08.001.

Bertaux, P. et al. (2009). The CLIL teacher's competences grid. Common Constitution and Language Learning (CCLL) Comenius-Network. Retrieved April 16 ${ }^{\text {th }}, 2017$, from http://ccll-eu.eu/cms02/index.php?id=62.

Chamot, A.U. \& B. Genovese. (2009). Using Student Choice in Foreign Language Teaching to Make Connections to Other Disciplines. Electronic Journal of Foreign Language Teaching, 6/2, 150-160. Retrieved June $5^{\text {th }}$, 2018, from http://eflt.nus.edu.sg/v6n22009/chamot.pdf.

Coyle, D. (2006). Content and Language Integrated Learning - Motivating Learners and Teachers. The Scottish Languages Review, 13, 1-18.

Gomez R., L. F. (2017). Learning by teaching: Training ELF pre-service teachers through inquiry-based learning. Electronic Journal of Foreign Language Teaching, 14/1, 21-36. Retrieved June $5^{\text {th }}$, 2018, from http://e-flt.nus.edu.sg/v14n12017/gomez.pdf. 
Graddol, D. (2006). English Next. Why global English may mean the end of "English as a Foreign Language". London: The British Council. Retrieved April 16 ${ }^{\text {th }}$, 2017, from http://englishagenda.britishcouncil.org/sites/ec/files/books-english-next.pdf.

Greere, A. \& Räsänen, A.. (2008). Year One Report. LANQUA Subproject on Content and Language Integrated Learning. Retrieved April 16 ${ }^{\text {th }}, 2017$, from http://www.lanqua.eu/sites/default/files/Year1Report_CLIL_ForUpload_WithoutApp endices_0/index.pdf.

Guillamón-Suesta, F. \& Renau Renau, M.-L. (2015). A critical vision of the CLIL approach in secondary education: A study in the Valencian Community in Spain. Latin American Journal of Content and Language Integrated Learning, 8/1, 1-12. Retrieved June $5^{\text {th }}$, 2018, from http://laclil.unisabana.edu.co/index.php /LACLIL/article/view/5037.

Haigh, M. et al. (2013). Judging teacher candidates' readiness to teach. Teaching and Teacher Education, 34, 1-11.

Hillyard, S. (2011). First Steps in CLIL: Training the Teachers. Latin American Journal of Content and Language Integrated Learning, 4/2, 1-12. Retrieved June $5^{\text {th }}, 2018$, from http://laclil.unisabana.edu.co/index.php/LACLIL/article/view/2631.

Karimi, M. (2011). Variations in EFL teachers' pedagogical knowledge base as a function of their teaching license status. The Journal of Teaching Language Skills, 3/3, 83-114. Retrieved June $5^{\text {th }}$, 2018, from http://jtls.shirazu.ac.ir/mobile/ article_379_6ccac0606c1d0033615189cac5dc52c2.pdf.

Moreno-Murcia, J. A. et al. (2015). Questionnaire evaluating teaching competencies in the university environment. Evaluation of teaching competencies in the university. Journal of New Approaches in Educational Research, 4/1, 54-61. Retrieved June $5^{\text {th }}$, 2018, from https://naerjournal.ua.es/article/view/106.

Nestojko, J. (2014). Expecting to teach enhances learning and organization of knowledge in free recall of text passages. Memory \& Cognition, 42/7, p.1038-1048. Retrieved June $5^{\text {th }}, 2018$, from https://link.springer.com/article/10.3758/s13421-014-0416-z.

Roscoe, R. D., \& Chi, M. T. H. (2007). Tutor learning: The role of explaining and responding to questions. Instructional Science, 36, 321-350. Retrieved June $5^{\text {th }}$, 2018, from https://www.jstor.org/stable/23372885?seq=1\#page_scan_tab_contents.

Stollhans, S. (2016). Learning by teaching: Developing transferable skills. In E. Corradini, K. Borthwick \& A. Gallagher-Brett (Eds.), Employability for languages: A handbook, 161-164. Dublin: Researchpublishing.net. Retrieved June $5^{\text {th }}, 2018$, from http://eprints.nottingham.ac.uk/34412/1/478.pdf.

Taillefer, G. (2013). CLIL in higher education: the (perfect?) crossroads of ESP and didactic reflection. ASp, 63, 31-53.

\footnotetext{
i “Arrêté du 27 août 2013 fixant le cadre national des formations dispensées au sein des masters métiers de l'enseignement, de l'éducation et de la formation" (NOR: ESRS1319419A). [https://www.legifrance.gouv.fr /eli/arrete/2013/8/27/ESRS1319419A/jo/texte]

ii "Référentiel des compétences professionnelles des métiers du professorat et de l'éducation", July 2013 (NOR : MENE1315928A). [http://www.education.gouv.fr/pid25535/bulletin_officiel.html?cid_bo=73066]

iii She did the final assignment nonetheless, focusing on the topic of "commitment" with fifth grade pupils.

iv This placement test was implemented by the ESPE management before the course started.

${ }^{v}$ The questionnaire was in French, so were the responses. All translations are mine.

${ }^{v i}$ One of the five goals established by the American Council on the Teaching of Foreign Languages (ACTFL) (Chamot \& Genovese, 2009, p.150).
} 